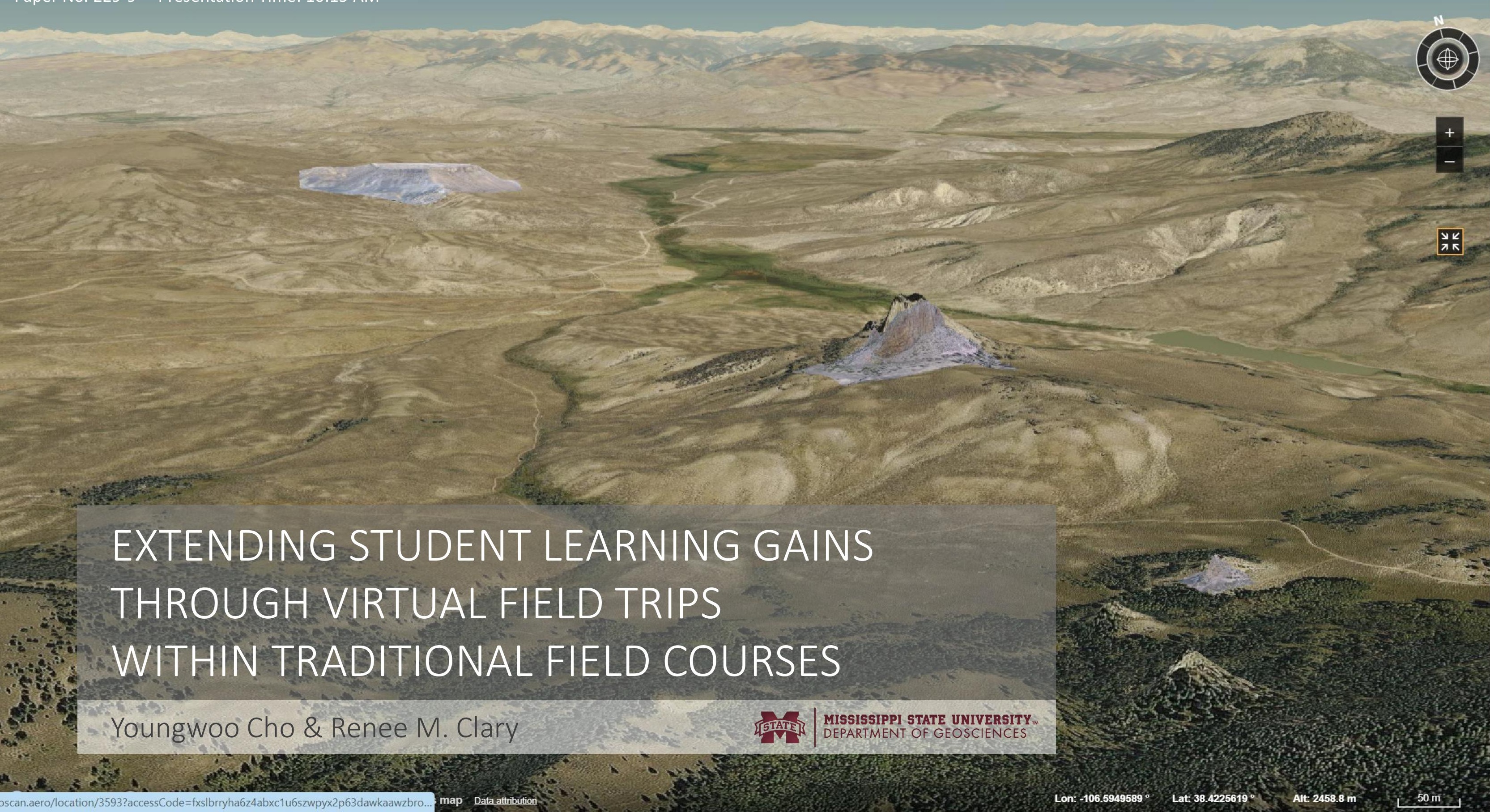

\title{
EXTENDING STUDENT LEARNING GAINS THROUGH VIRTUAL FIELD TRIPS WITHIN TRADITIONAL FIELD COURSES
}




\section{MSU-USM's Summer Geology Field Camp 2018}

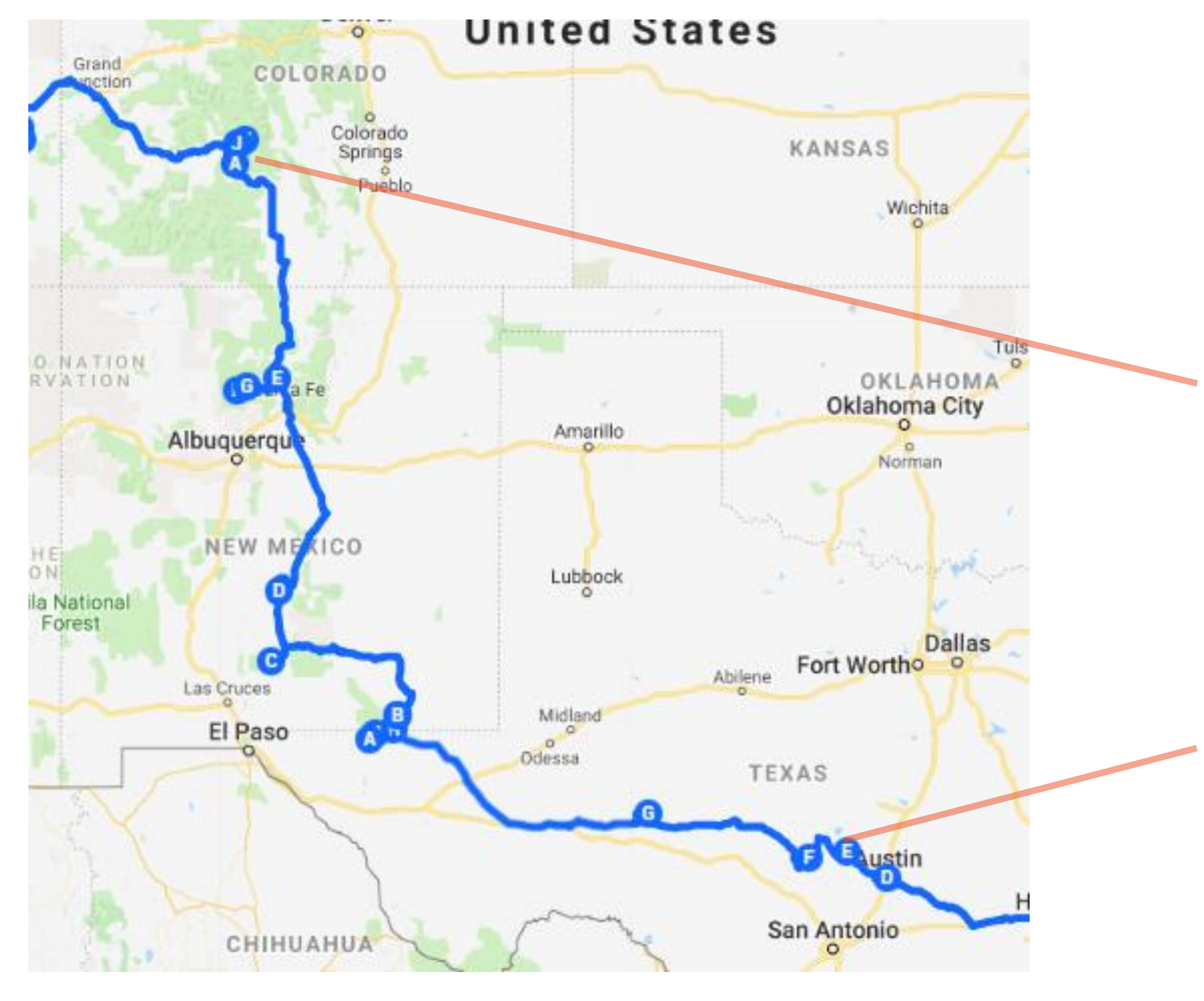

Saguache County, CO

- 3D rock models

- 3D map app with DTMs

- Virtual tour

Hoover Point outlook near Kingsland, TX

- Gigapixel image of a roadcut 


\section{Virtual Tools Developed in this Project:}

- Tiled Gigapixel images

- 3D Rock Models

- 3D map platform with tiling capability

- Virtual tour with 360-degree panoramas 
$\square$ 2-dimensional image with huge dimension which is zoomable to show the entire view and the small details of with one single image.

$\square$ A roadcut near Hoover Point overlook

口 Canon 5D Mark IV + EF 24 mm lens

ㅁ 126 images (An image in every $1.5 \mathrm{~m}$ )

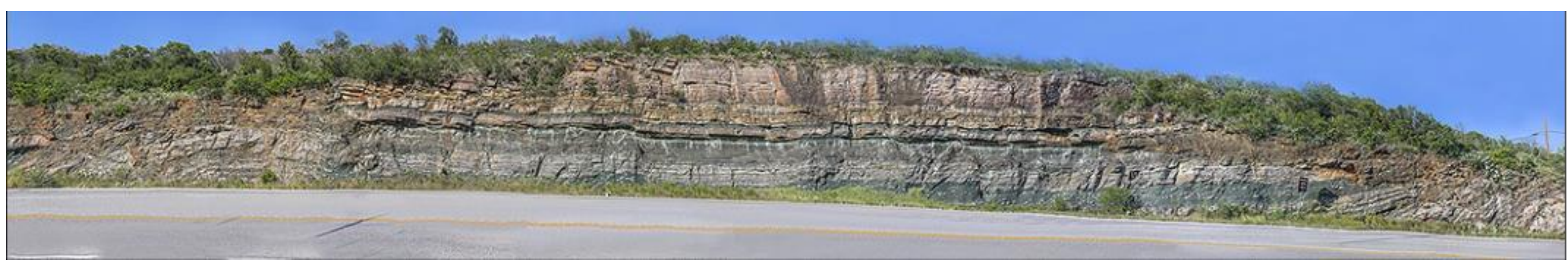

$600 \mathrm{ft}$ or $200 \mathrm{~m}$ 


\section{Tiled Gigapixel Images}

$\square$ Goal: To show larger geologic features such as stratigraphy and geological structures, and smaller features such as small structures and textures.

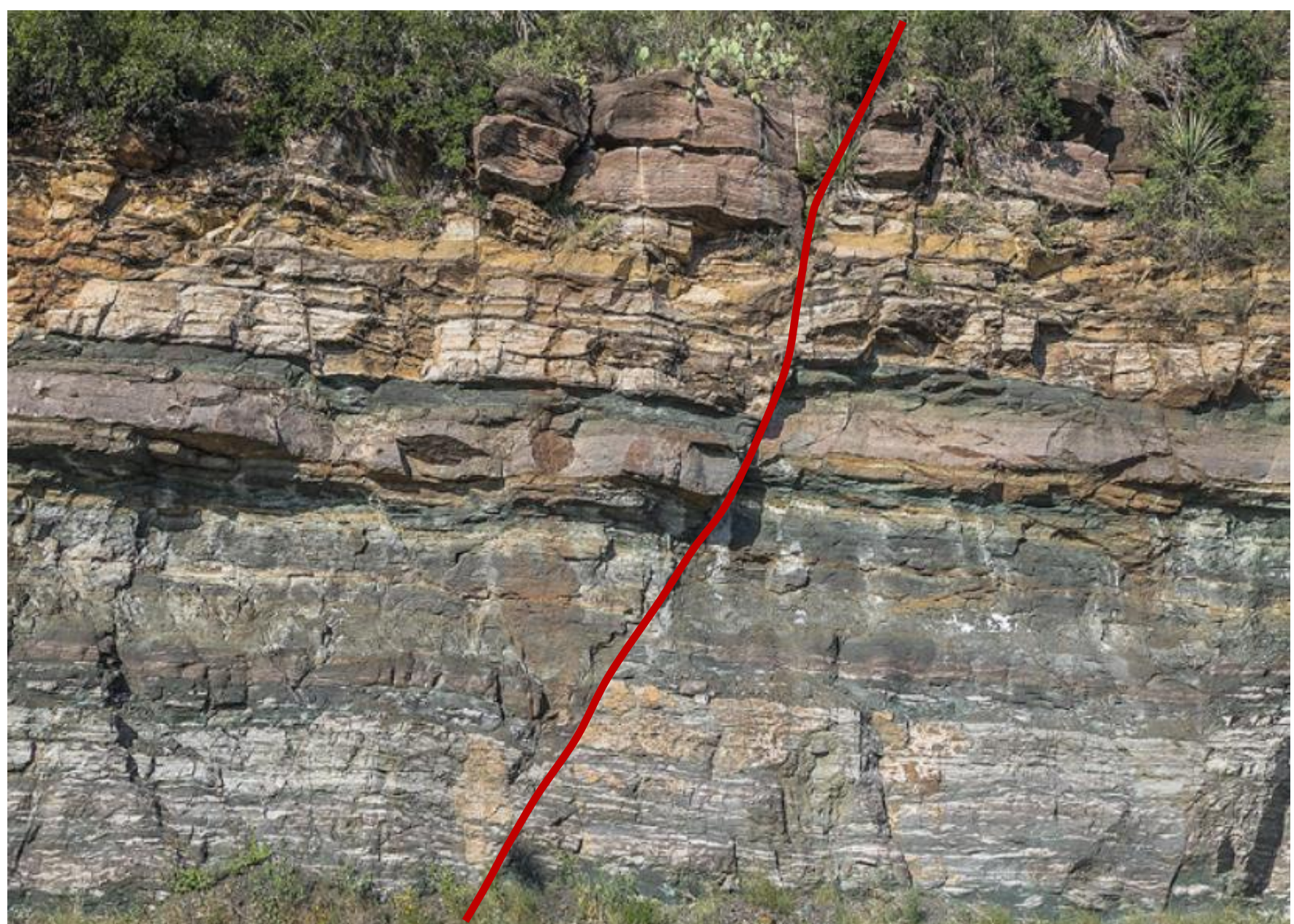




\section{Tiled Gigapixel Images}

$\square$ Actual field analogy: we want to see the entire view from far and want to get closer to see more details.

$\square$ Features: Continuously changes between the entire view and the detailed view "very quickly" due to the tiling capability.

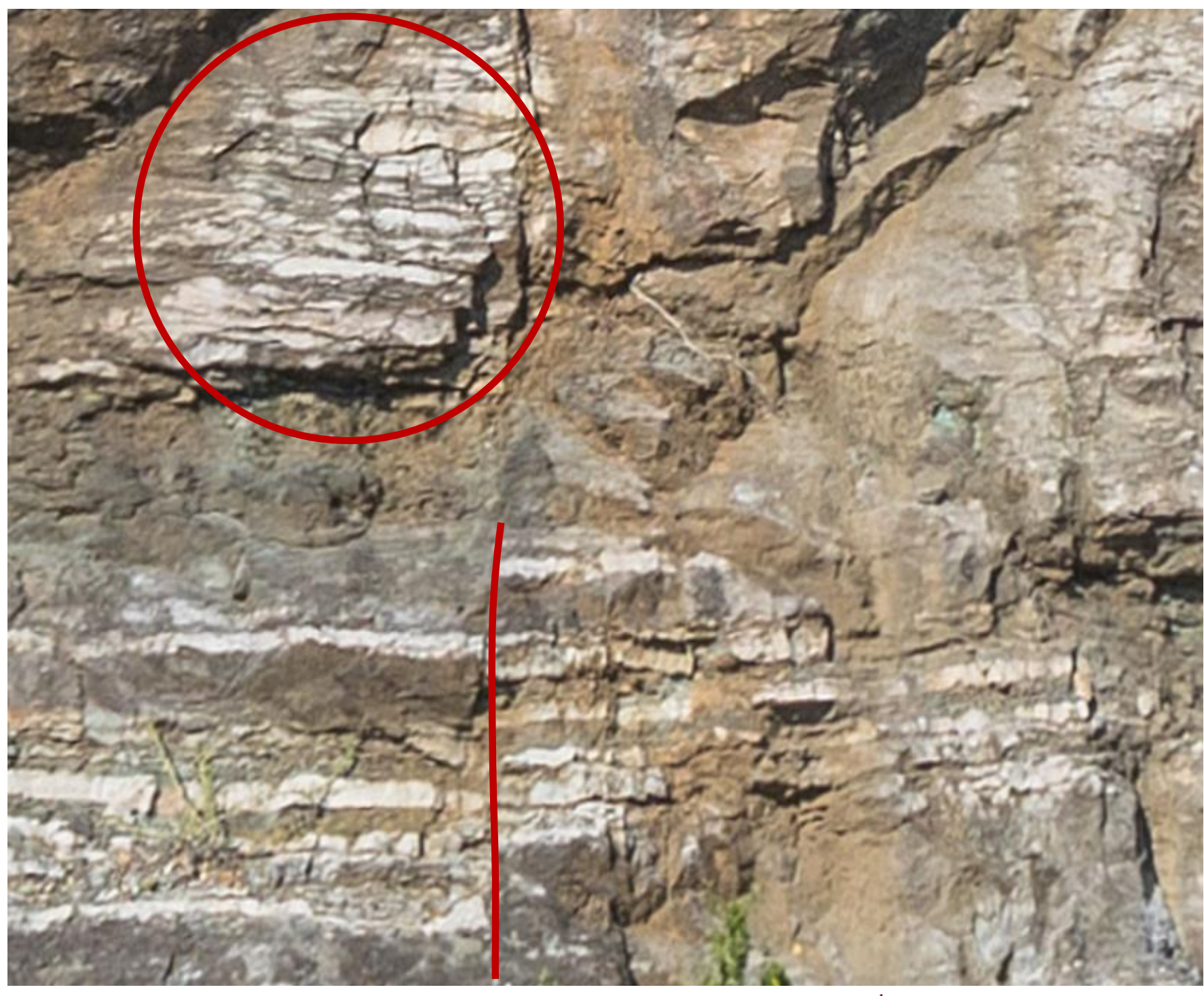


$\square$ Tool: Software stitching images into a panorama (Autopano Giga or another panorama stitching software)

$\square$ Data: High quality images captured on stable support and with enough overlaps. 


\section{Tiled Gigapixel Images}

\section{Feedback}

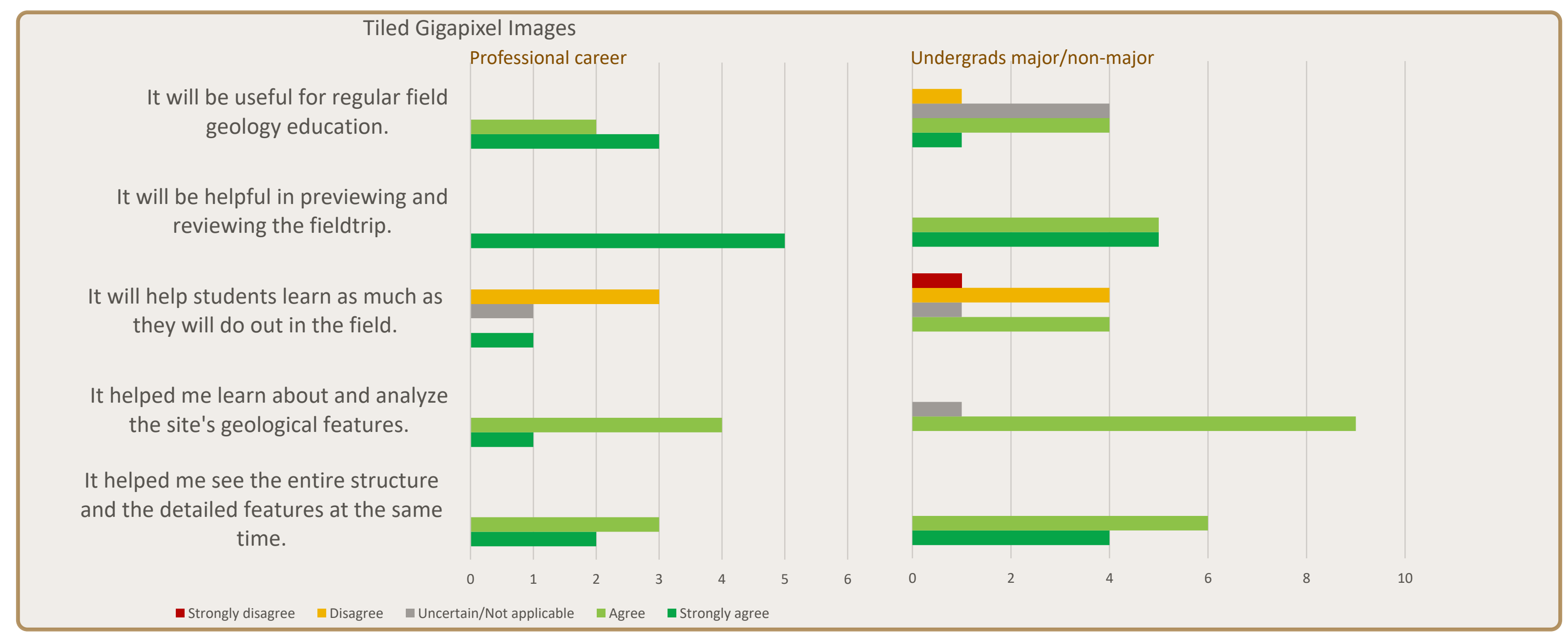


- Virtual 3-dimensional representation of specimens of rocks and fossils

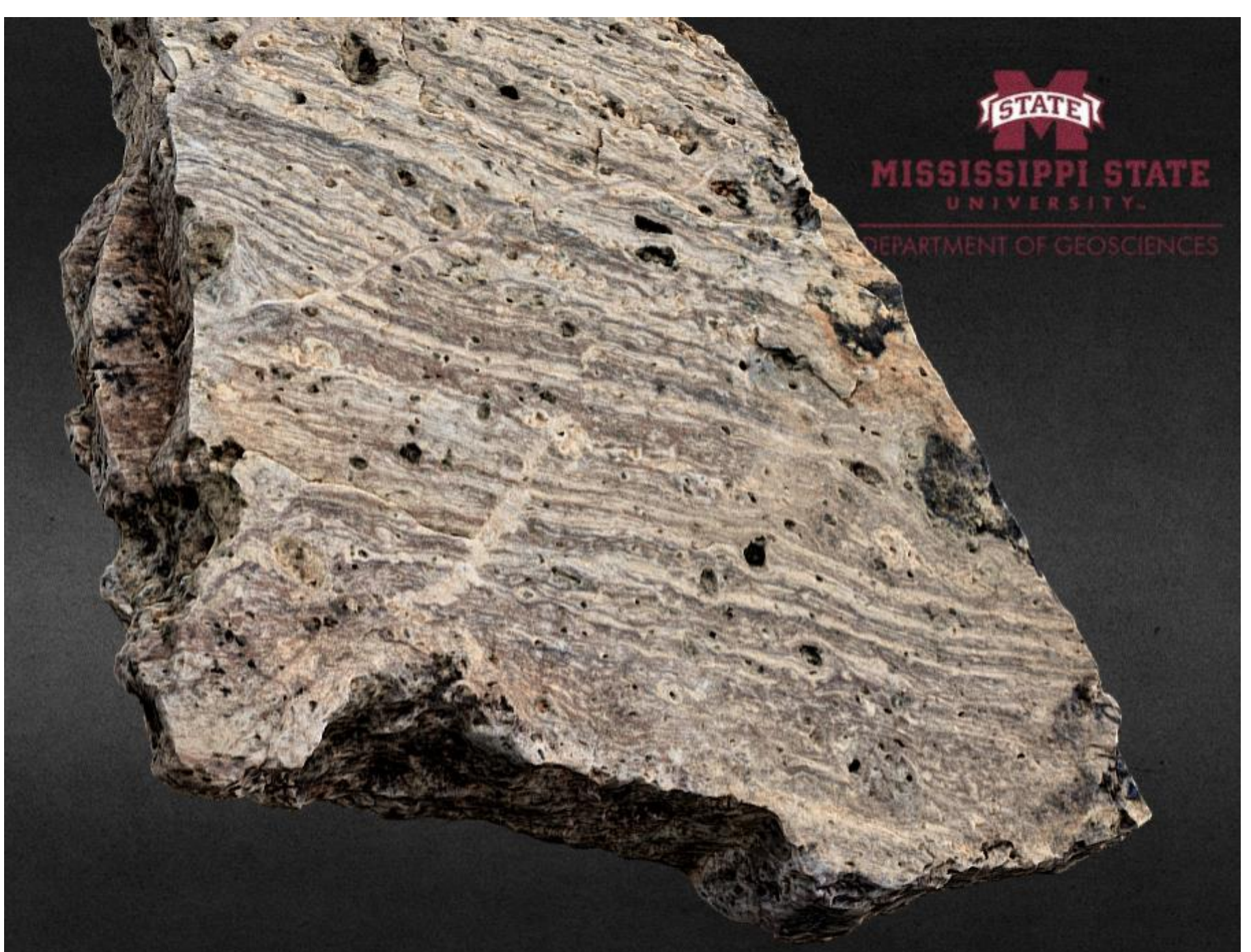

Rhyolite from Prosser Rock, https://skfb.ly/6CGHq

https://sketchfab.com/yow 
$\square$ Goal: To provide visual inspection of specimens of rocks and fossils.

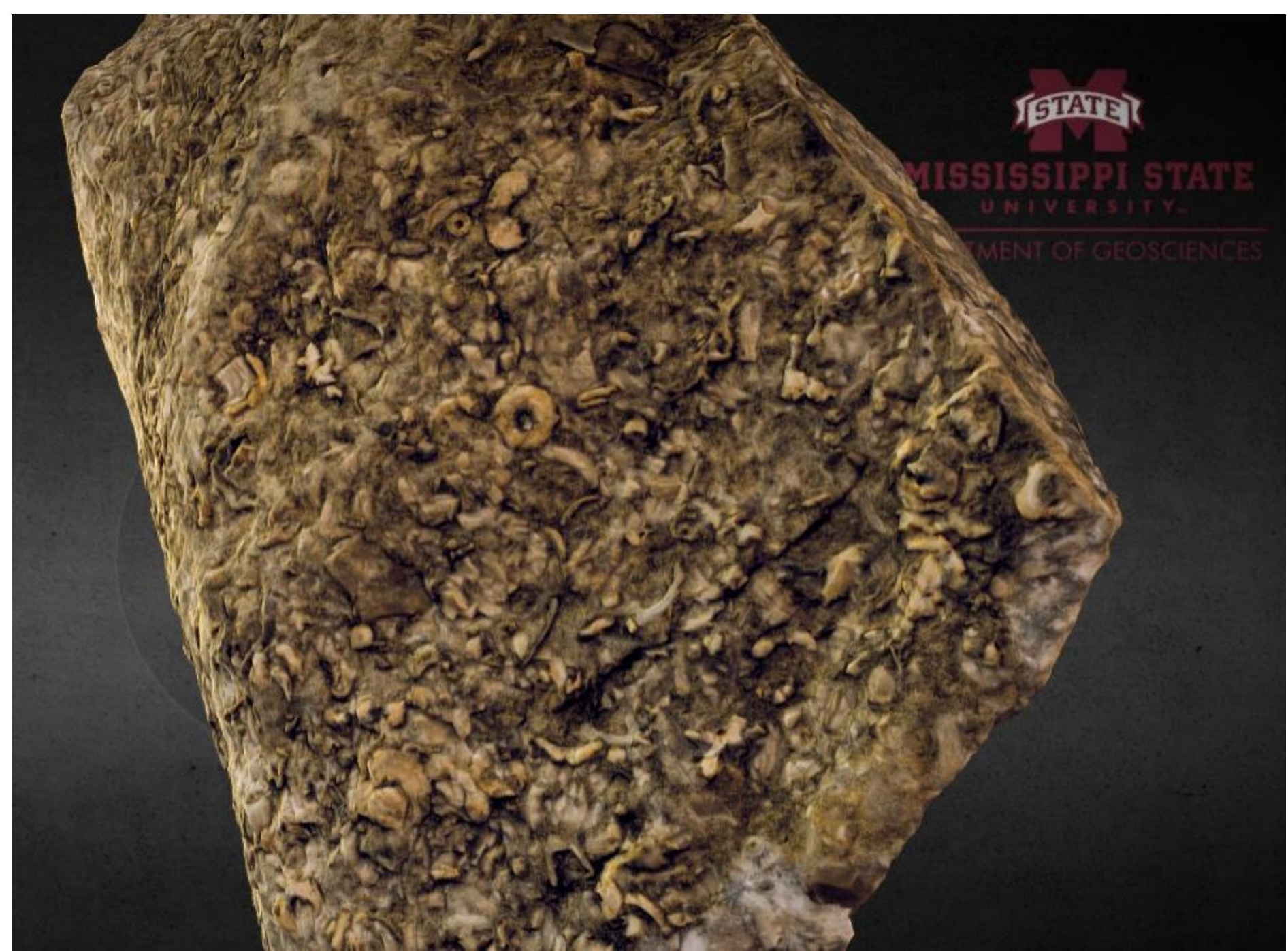

Fossiliferous limestone from the laboratory repository, https://skfb.ly/6CvUU 
$\square$ Actual analogy: Holding a hand sample to inspect it (without a magnifier).

$\square$ Features: Rotatable and zoomable.

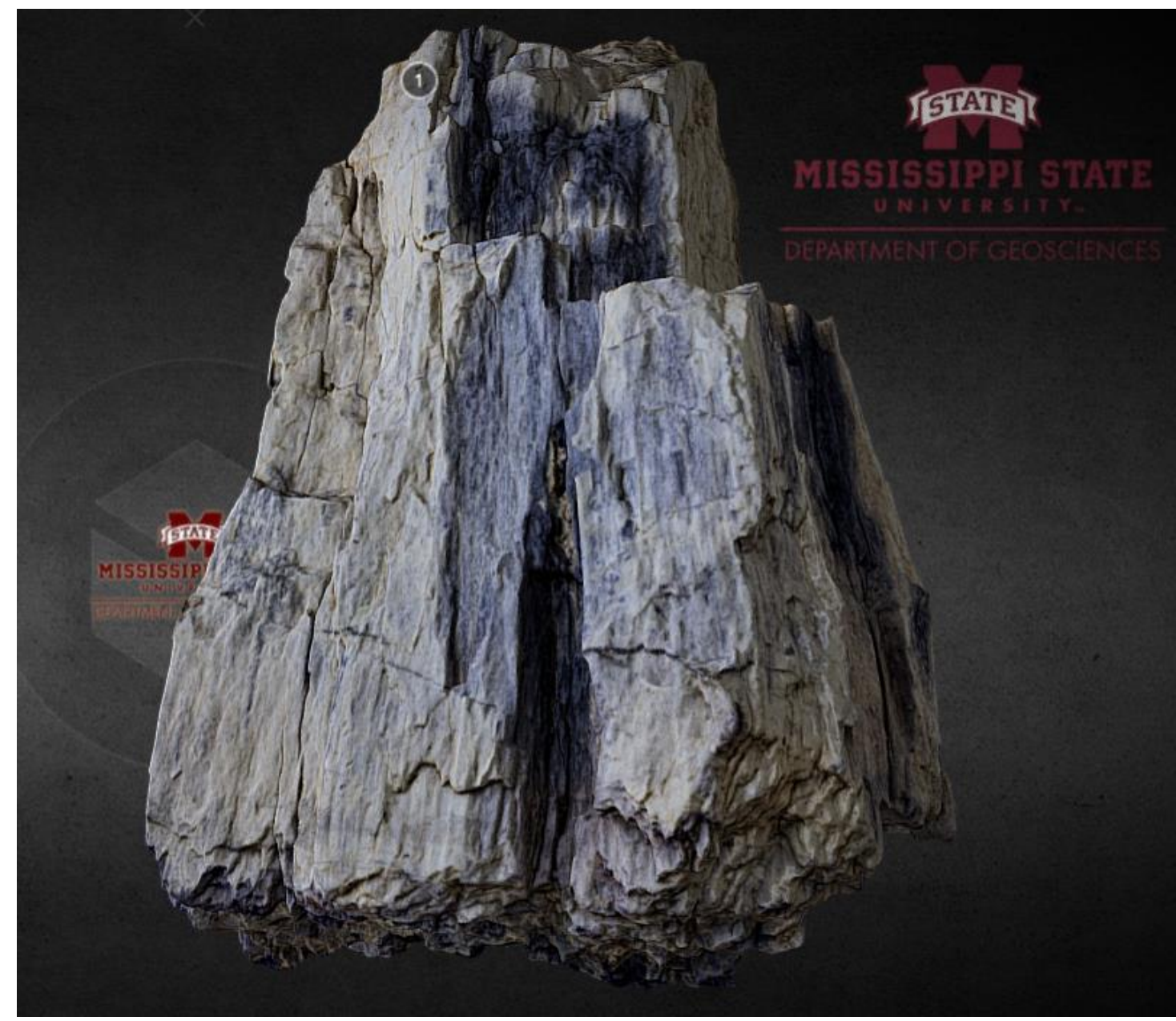




\section{D Rock Models}

$\square$ Tools:

口 3-axis motion control hardware and turntable, lightbox, and Canon 5D Mark IV DSLR + EF 50mm 1:2.8 Macro Lens

- Software packages for photo-shooting with exposure and focus bracketing capabilities, High Dynamic Range (HDR) image composite, focus stacking, retouching, and Structure-from-Motion (SfM) and Multi-View Stereo (MVS) photogrammetry.

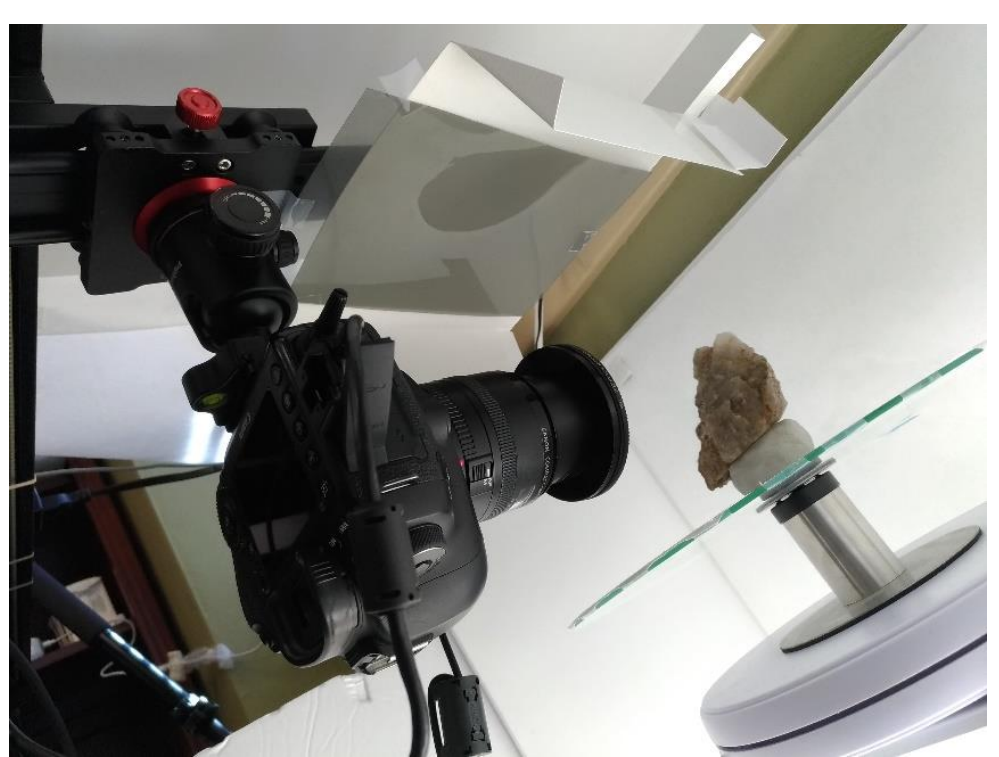

Data:

For petrified wood specimen - total 11,972 raw images, 3,801 HDR images, 277 focus-stacked images (Upside $109+$ downside $118+$ common 50) 


\section{D Rock Models}

\section{- Feedback}

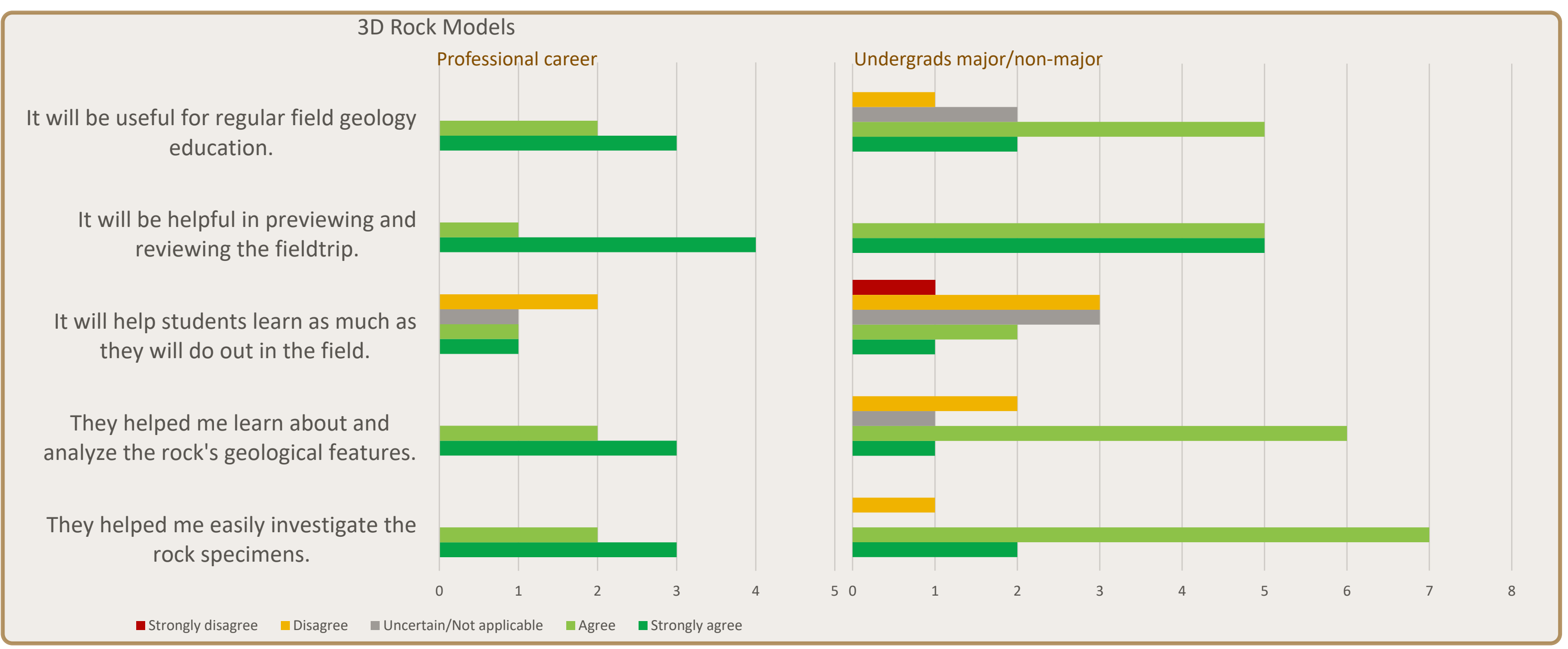




\section{D Map Platform with 3D Tiling Capability}

3-dimensional map platform for tiling 3D geospatial data (terrain models)

Sputnik Web

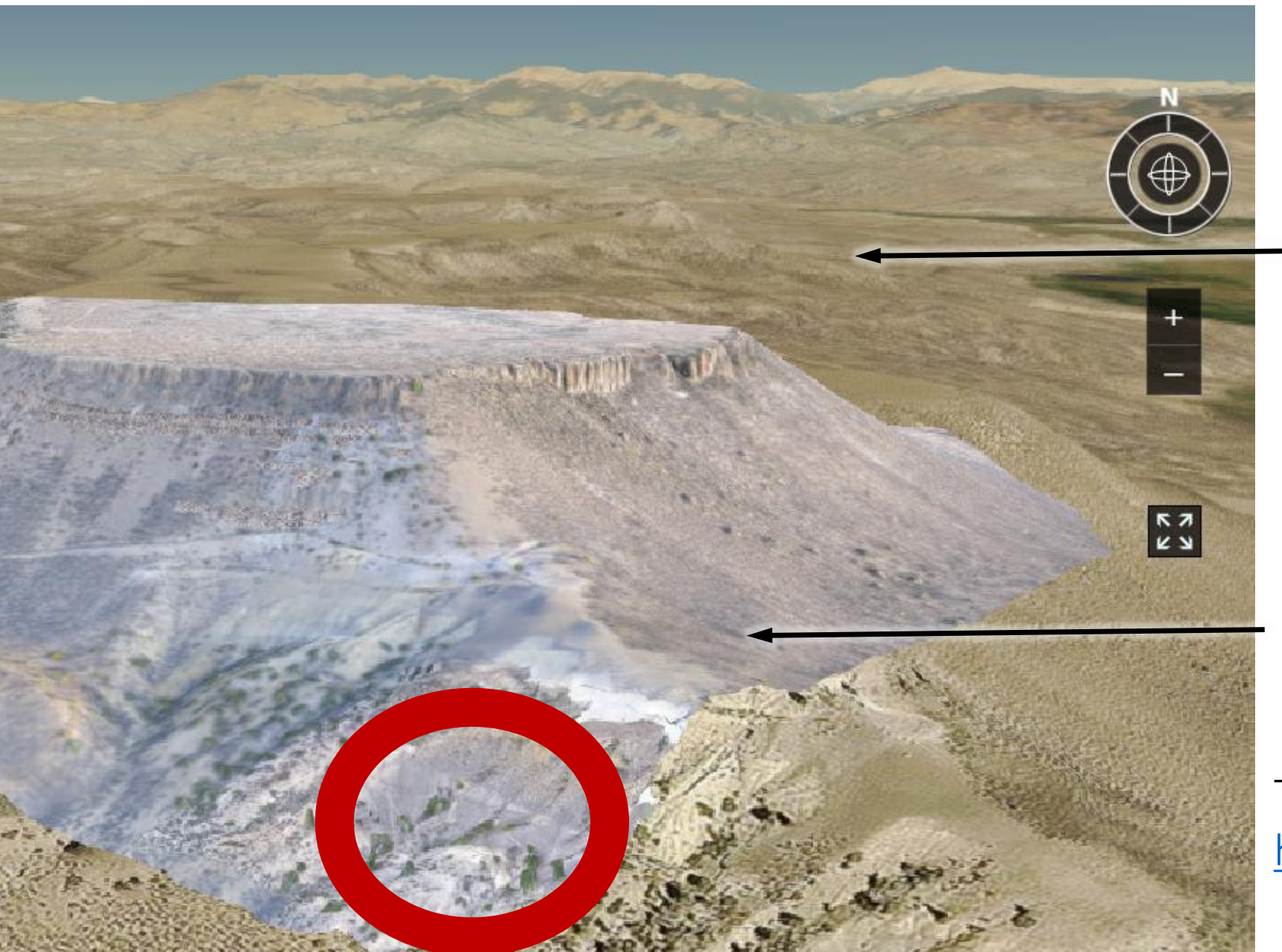

3D Terrain Model

3D Base Map

Table Top

https://bit.ly/2QlHrFG

\begin{tabular}{l|l} 
IFTATPRPAP & $\begin{array}{l}\text { MISSISSIPPI STATE UNIVERSITY } \\
\text { DEPARTMENT OF GEOSCIENCES }\end{array}$
\end{tabular} 


\section{D Map Platform with 3D Tiling Capability}

$\square$ 3-dimensional map platform for tiling 3D geospatial data (terrain models)

3D Terrain Model

Table Top,

https://bit.ly/2QlHrFG

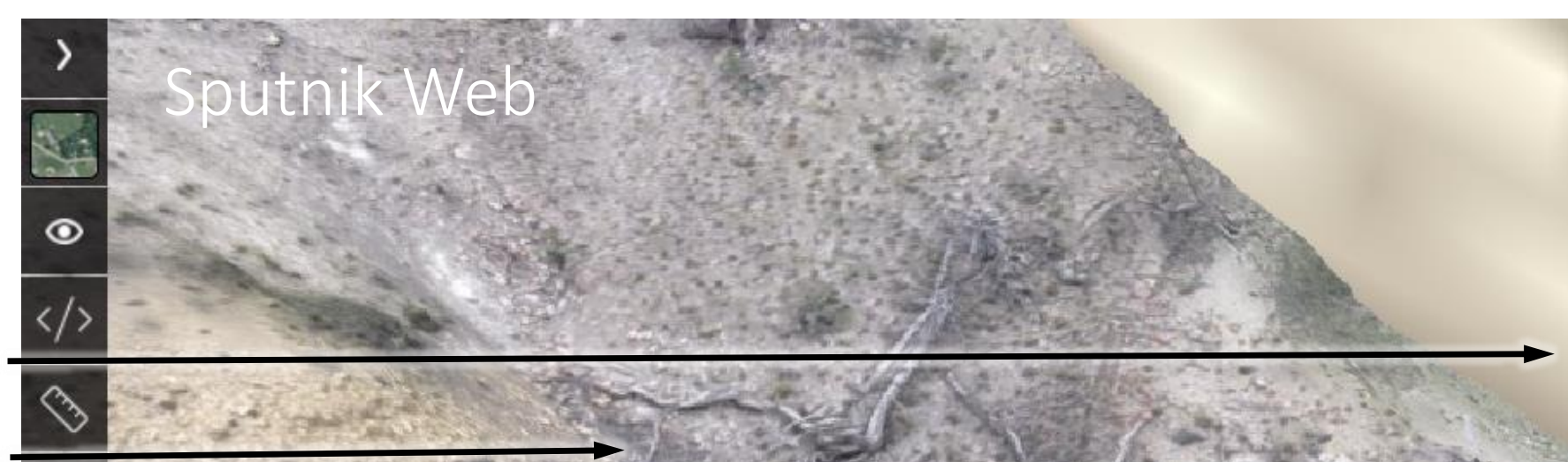

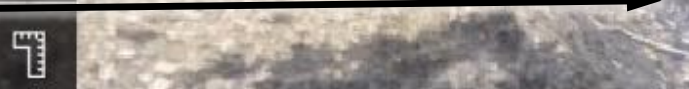

四

a

o

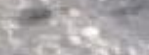

U

.

四
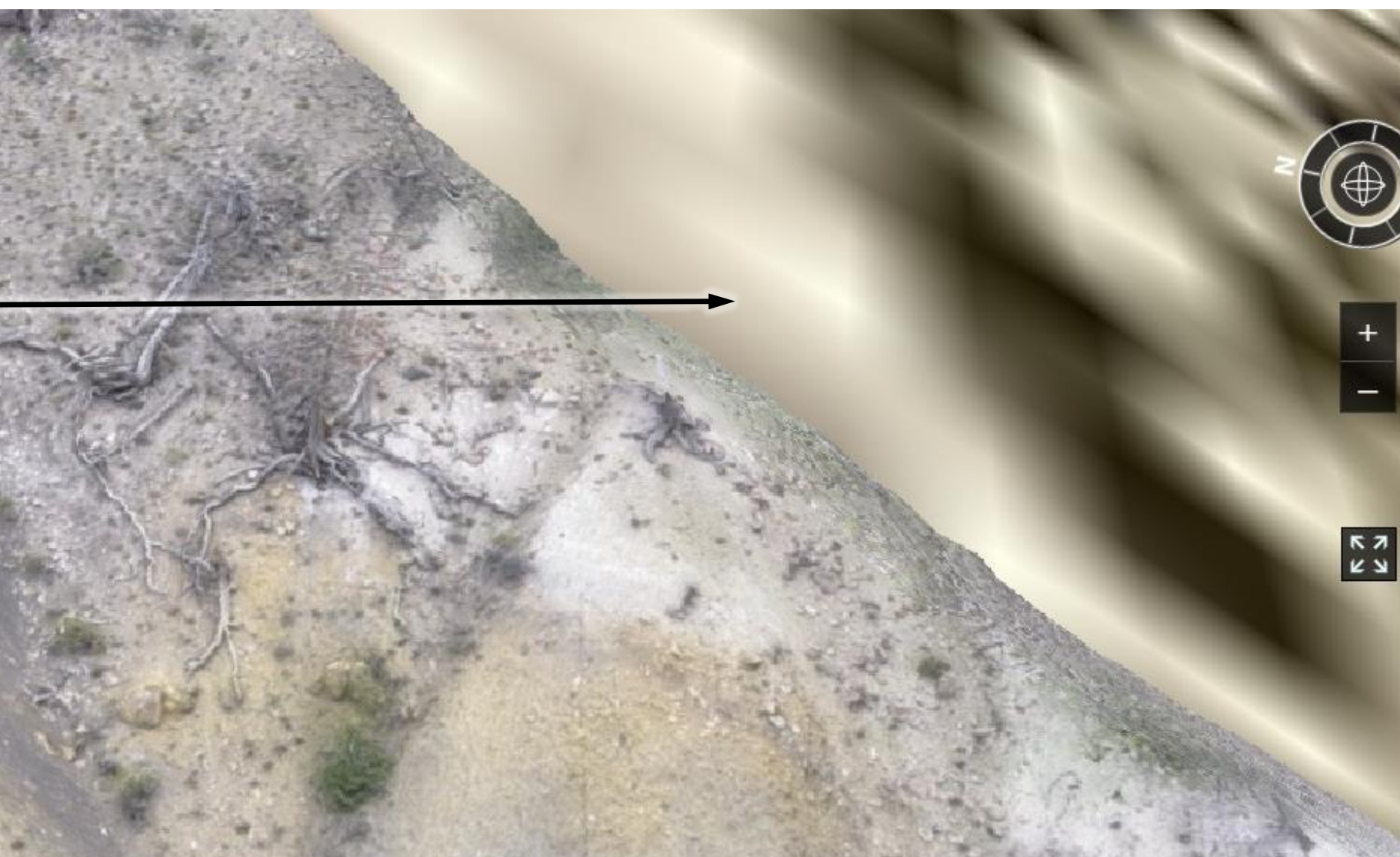

$+$

$-$

Ka

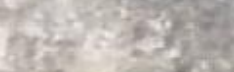

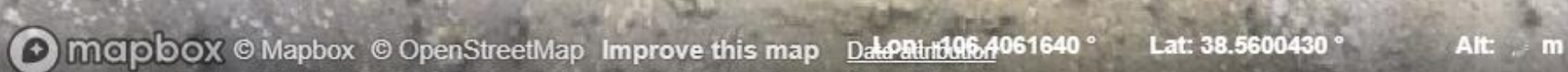




\section{D Map Platform with 3D Tiling Capability}

- Goal: To look at geographical relationships and to measure geospatial quantities such as location, direction, distance, height, length, area, and volumes; plus visual inspection with a higher resolution than the base map.

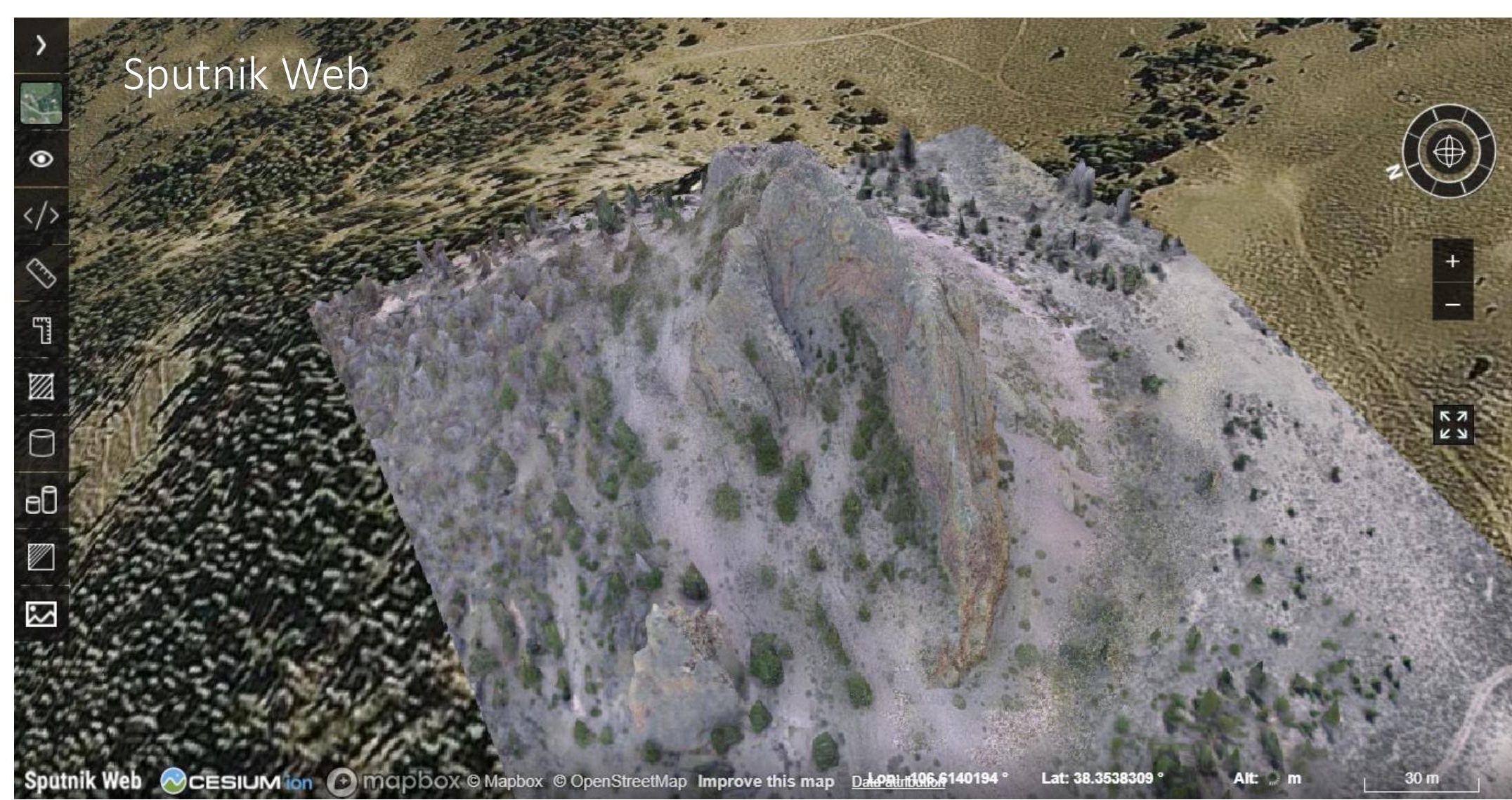




\section{D Map Platform with 3D Tiling Capability}

$\square$ Actual analogy: Take a helicopter hovering over an area of interest inspecting geologic features with geospatial information.

$\square$ Features: 3-dimensional base map which is overlain by terrain models with higher resolution.

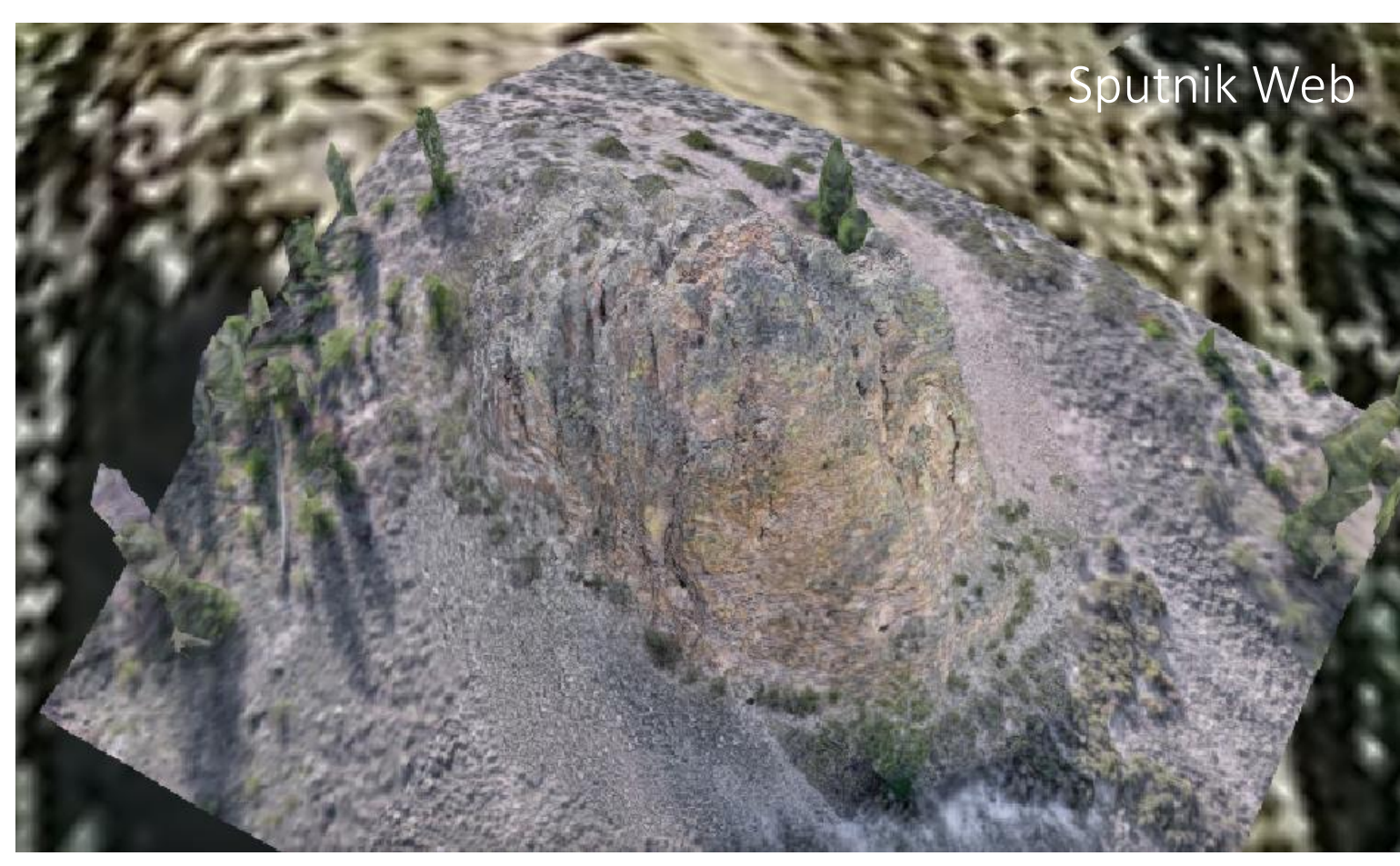


$\square$ Tools:

$\square$ UAV (DJI Phantom 4)

$\square$ Software packages for photo-shooting with exposure bracketing capabilities, High Dynamic Range (HDR) image composite, retouching, and Structure-from-Motion (SfM) and Multi-View Stereo (MVS) photogrammetry.

$\square$ Data: For P2 - total 1,305 raw images, 435 HDR images 


\section{D Map Platform with 3D Tiling Capability}

$\square$ Cesium ION

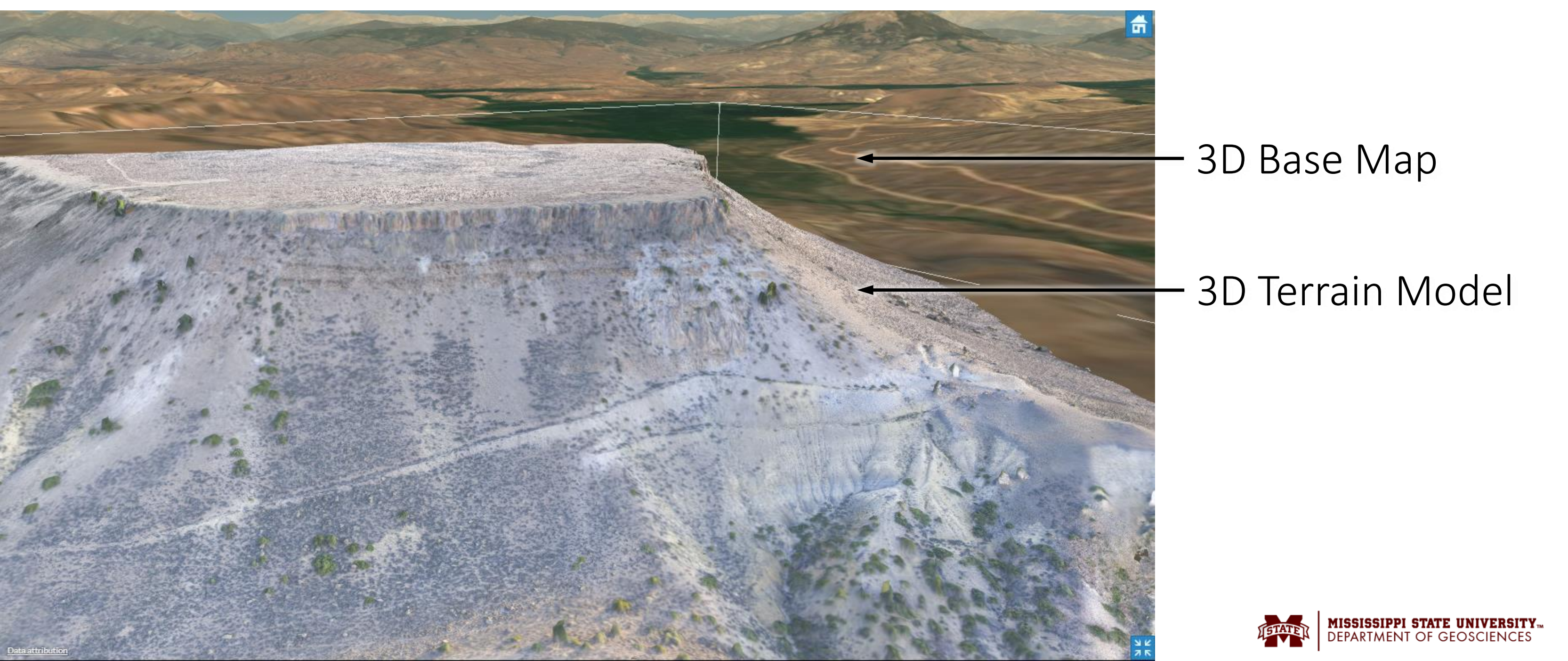




\section{D Map Platform with 3D Tiling Capability}

$\square$ Feedback

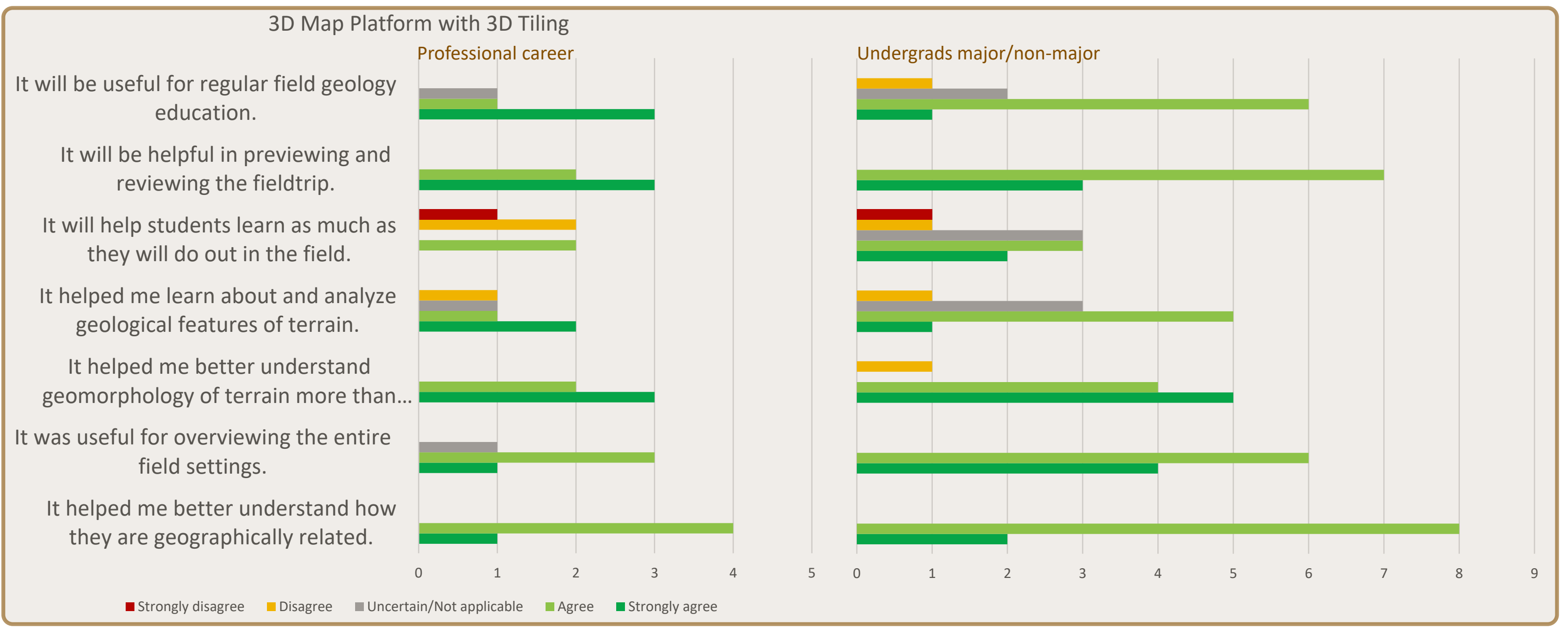

-Strongly disagree $\square$ Disagree $\quad$ Uncertain/Not applicable $\square$ Agree $\square$ Strongly agree 


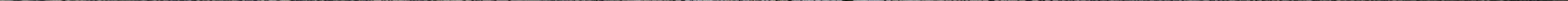




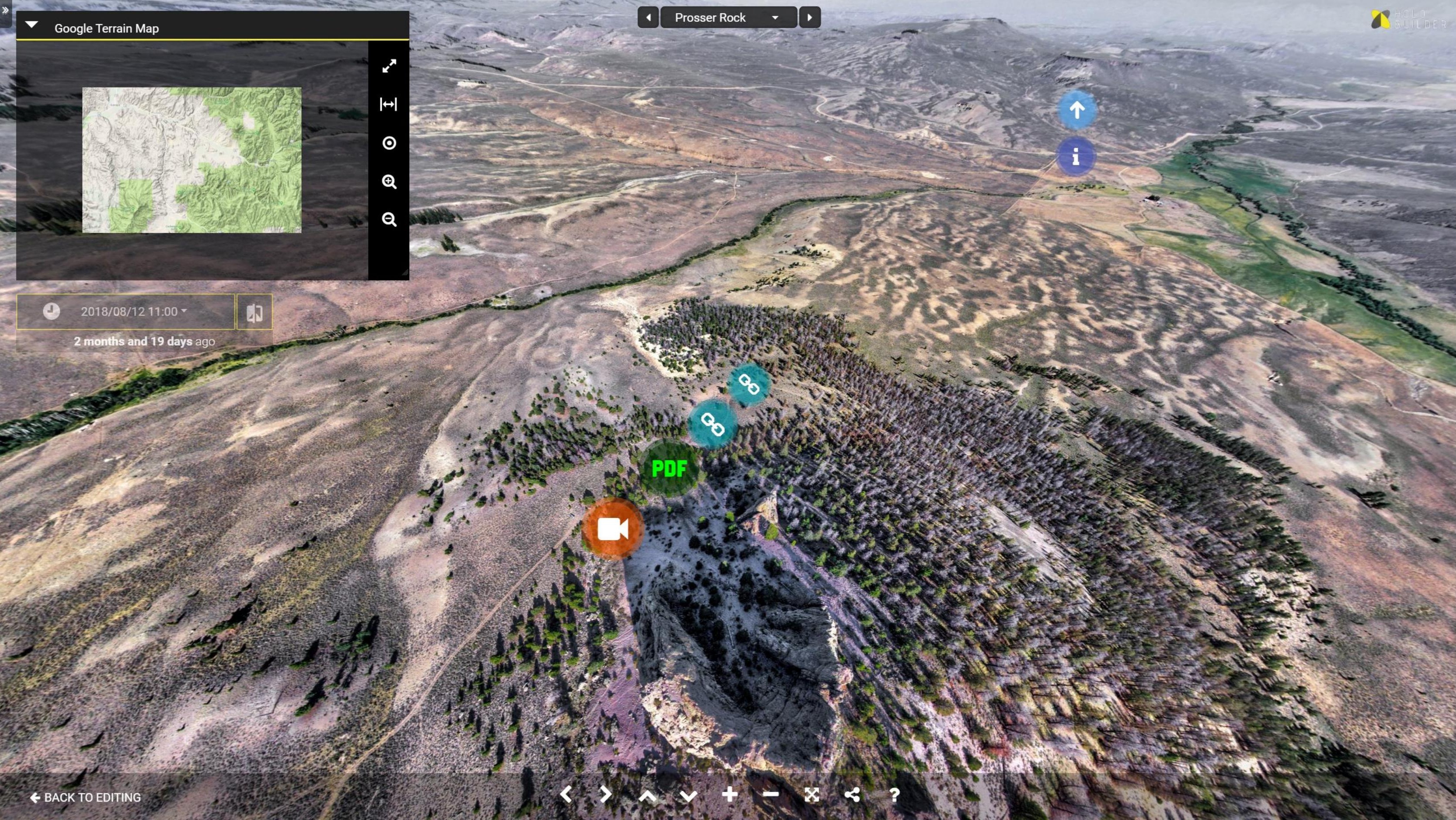




\section{Virtual tours using 360 panoramas}

$\square$ Tools:

$\square$ 360-degree panorama stitching software, virtual tour creation software or virtual tour hosting website.

$\square$ Data: About 30-50 aerial images taken over an area of interest, sky panorama pictures to build hemispheric sky. 


\section{Virtual tours using 360 panoramas}

\section{- Feedback}

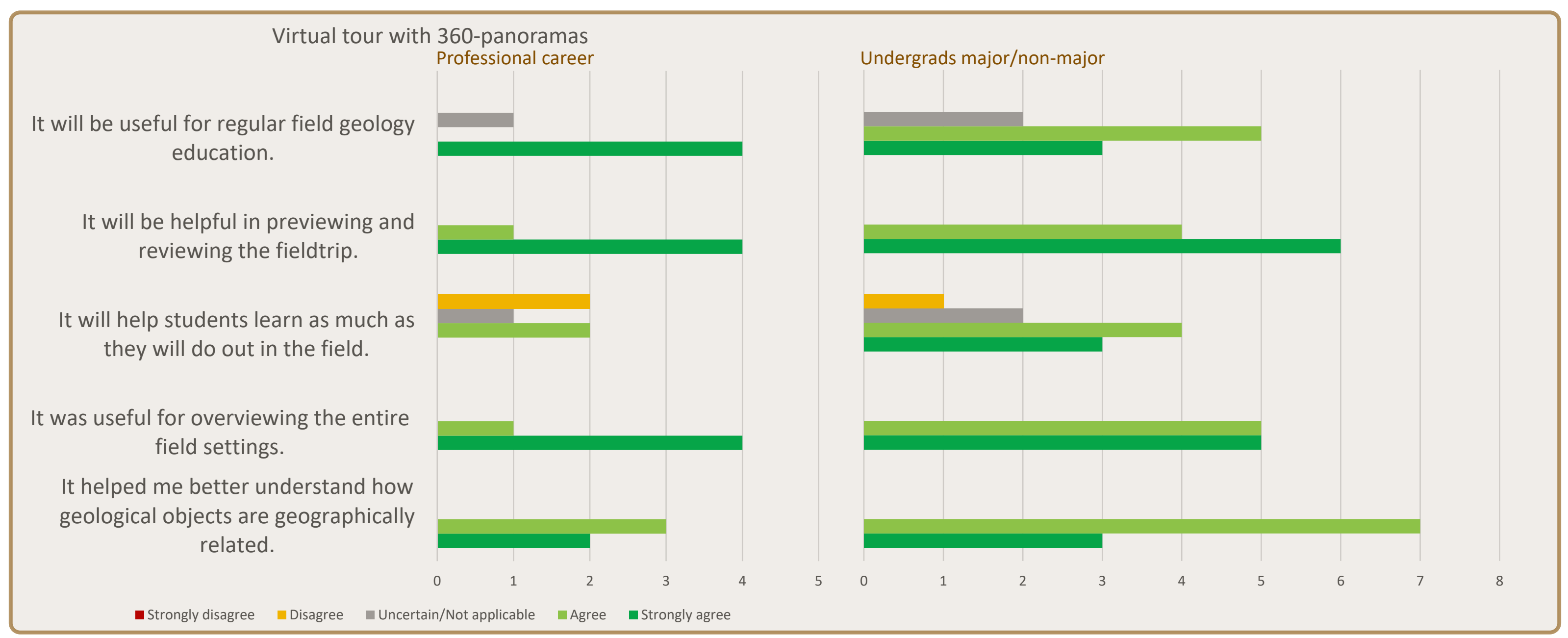




\section{The Entire Set of Virtual Tools collectively}

\section{- Feedback}

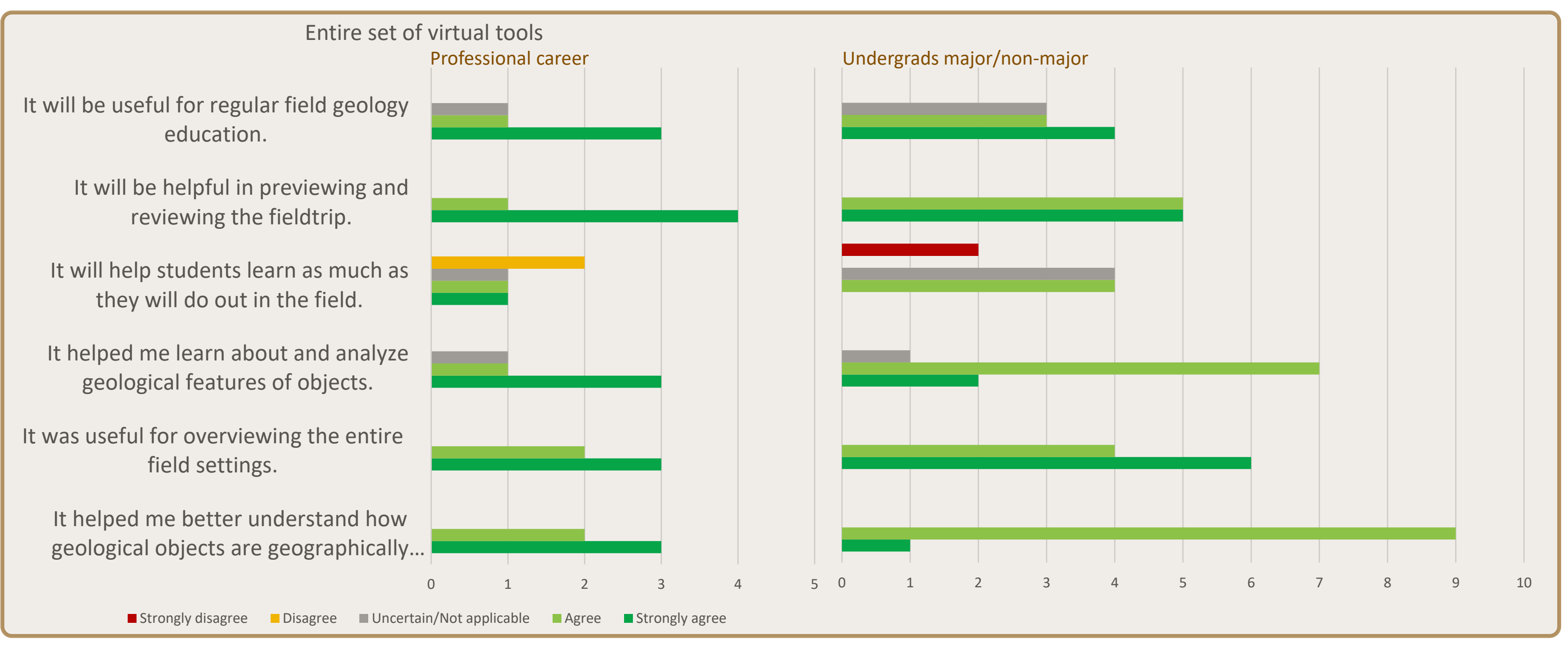




\section{The Entire Set of Virtual Tools collectively}

- Feedback

$\square$ Collectively, these materials will certainly be appropriate for a field overview and provide good levels of detail. Small, but essential, geological details (i.e., slickensides, physical declivities, textural gradations) are not fully captured at both the outcrop and study area scales.... Overall, this work is important and I'm optimistic that it will contribute much to geological education.

- There is certainly a lot of good things happening with this work and the ability to be a supplemental or supportive resource is very exciting. However, optimization of the visual elements or perhaps an external source that does not rely on internet may be something worth looking into. The internet at Pitkin is about as good as what I have at home. 


\section{The Entire Set of Virtual Tools collectively}

\section{Feedback}

$\square$ The design and layout of some items could also be improved slightly to allow more control by the user. I don't think it could ever replace the field camp experience, but certainly if a field camp was monetarily limited some field work could be done with this material in order to help teach the methods of field geology and how one may approach a particular investigation of the rock material. More than anything, I think this is a great resource for outreach and would be great for helping people/students gain a passion for the geosciences.

$\square$ I think the strength of visual tools like these lies in the collection rather than the individual components. By compiling all of these different visual and informational components it makes the topic easier to see and understand as a whole. 


\section{Conclusion and Discussion}

$\square$ All virtual tools need to have an appropriate scale. (In preparation)

$\square$ All virtual tools need to have appropriate annotations and markups. (In preparation)

$\square$ Tiled Gigapixel images still need to be improved by providing better details when it was zoomed into the maximum possible level.

- 3D rock models have good resolution but in some cases they lack detail. (Those dead areas should be carefully inspected and need to have more overlapping pictures.) 


\section{Conclusion and Discussion}

$\square$ 3D map platforms need to be improved most in visually aspects. (Aerial pictures need to be taken with even higher details; need to get closer and more overlaps)

V Virtual tour with 360-degree panoramas need to allow movement inside the scene? - technically not possible yet and partially can be solved by adding more scenes and time-travel options.

$\square$ Virtual tools can prove their worthiness collectively as a set. 


\section{References}

Cho, Y. \& Clary, R. M. (2017, February). Application of SfM-MVS Photogrammetry in Geology Virtual Field Trips, Paper presented at the 81 st annual meeting of Mississippi Academy Sciences, Hattiesburg, MS, USA

Cho, Y. \& Clary, R. M. (2017, October). Creating a Virtual Field Trip using a 3D Game Engine and Photographic 3D Models from the Real World, Paper presented at the annual meeting of the Geological Society of America, Seattle, WA, USA. doi: 10.1130/abs/2017AM-299609

Cho, Y. \& Clary, R. M. (2017, November). Use of UAVs in Virtual Field Trips, Paper presented at the annual meeting of the SouthEastern Division of the Association of American Geographers, Starkville, MS, USA

Cho, Y. \& Clary, R. M. (2018, February). Effective Design and Rendering of Photogrammetric Assets for Virtual Field Trips, Paper presented at the 82 ${ }^{\text {nd }}$ annual meeting of Mississippi Academy Sciences, Hattiesburg, MS, USA

Cho, Y. \& Clary, R. M. (2018, November). Creating Virtual Field Trips using 3D Models, Gigapixel images, and 360-degree Panoramas in Saguache County, Colorado, Paper presented at the annual meeting of the Geological Society of America, Indianapolis, IN, USA. doi: 10.1130/abs/2018AM318709

CesiumJS - Geospatial 3D Mapping and Virtual Globe Platform. (n.d.). Retrieved October 17, 2018, from https://cesiumjs.org/

Geoscan. (n.d.). Sputnik Web - General information. Retrieved October 17, 2018, from https://sputnik.geoscan.aero/about\#tutorialContent

Cesium. (n.d.). Cesium ion Docs. Retrieved October 17, 2018, from https://cesium.com/docs/

HoloBuilder Tutorials - Learn How to Use HoloBuilder for Efficient $360^{\circ}$ Construction Reality Capturing. (n.d.). Retrieved October 17, 2018, from https://www.createholo.com/

GIGAmacro. (n.d.). Upload Formats for GIGAmacro Viewer. Retrieved October 17, 2018, from http://docs.gigamacro.com/tiling/ 


\section{ACKNOWLEDGMENT}

TRAVEL TO COLORADO \& HIGH-PERFORMANCE COMPUTING:

\begin{tabular}{l|l} 
ISTATES & $\begin{array}{l}\text { MISSISSIPPI STATE UNIVERSITY } \\
\text { DEPARTMENT OF GEOSCIENCES }\end{array}$
\end{tabular}

TRAVEL TO GSA INDIANAPOLIS:

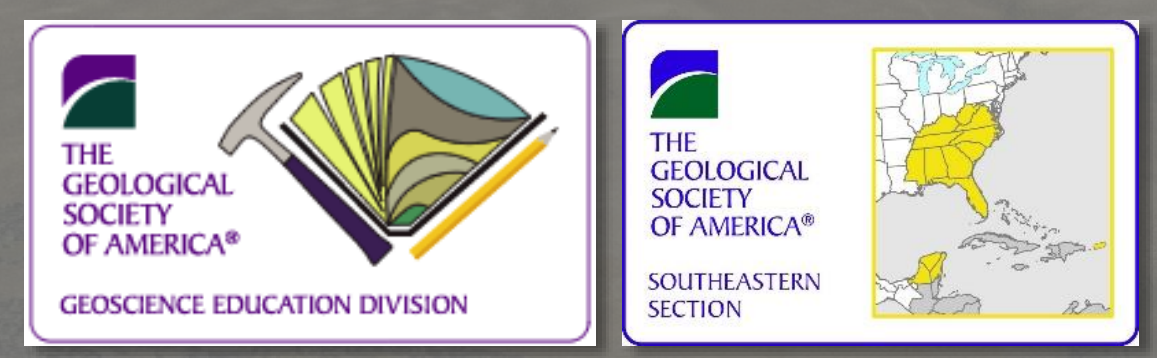

